\title{
Ternary Blends Containing Slag and Interground/Blended Limestone: Hydration, Strength, and Pore Structure
}

\author{
Aashay Arora ( $\left.{ }^{2}\right)$, Gaurav Sant ${ }^{3}$, Narayanan Neithalath $\left({ }^{*}\right)$
}

\section{ABSTRACT}

The influence of high volume cement replacement using a combination of slag and limestone, on the hydration, reaction products and pore structure, and strength of cementitious systems is reported in this paper. Total replacement levels vary from $20 \%$ to $50 \%$ by volume. Slag is blended with: (i) portland-limestone cement (PLC) that contains limestone interground with cement, or (ii) OPC and limestone of four different sizes in such a way that the resulting particle size distribution of the composite matches that of the corresponding PLC-based mixture. The hydration response of cement and cement-slag mixtures are found to be modified in the presence of limestone. It is observed from calorimetric and thermogravimetric analysis that a favorable slag-limestone synergy exists, that enables high volume replacement of cement without concomitant loss in properties. The early-age compressive strengths are beneficially impacted by the presence of limestone whereas the clinker factor does not play a significant role in later-age strengths in both the blended and interground systems. The study paves the way for development of multiple-material binders containing higher levels of cement replacement that demonstrate early and later age properties that are comparable to or better than that of traditional straight cement systems.

Keywords: Slag, Limestone, Interground Cements, Blended Cements, Hydration, Pore Structure

2 School of Sustainable Engineering and the Built Environment, Arizona State University, Tempe AZ 85287 (aashay.arora@asu.edu)

3 Assistant Professor, Department of Civil and Environmental Engineering, University of California Los Angeles, Los Angeles CA; Member, California Nano Systems Institute (gsant@ucla.edu)

$4{ }^{*}$ School of Sustainable Engineering and the Built Environment, Arizona State University, Tempe AZ 85287 (Narayanan.Neithalath@asu.edu); Corresponding Author. Phone: 001-480-965-6023; Fax: 001480-965-0557 


\subsection{INTRODUCTION}

27 The environmental impact, particularly the significant emission of greenhouse gases associated with the manufacture of ordinary portland cement (OPC) (1), has catalyzed studies on the use of several environmentally benign alternate materials as partial OPC replacements. Fine limestone powder is one such material that has shown to be a viable partial OPC replacement material. Limestone can be interground with OPC clinker in the cement manufacturing process or be ground separately and then blended with the cement during the concrete batching process. Improved particle packing, fine limestone acting as nucleation sites for reaction product formation, and consequently better properties are obtained with interground portland limestone cements (PLC) as well as systems where fine limestone is blended with plain OPC in the concrete production process (2-4).

Binary and ternary cementitious blends containing fly ash, ground granulated blast furnace slag (GGBFS, hereinafter referred to as slag), metakaolin or silica fume are being commonly used to produce sustainable high-performance concretes (5-7). Recently, significant work has been carried out on developing ternary blends based on the idea that limestone is capable of chemically combining with the aluminate phases in the cementitious materials to form carboaluminates that further densify the microstructure and consequently improve concrete properties (8-10). Synergistic effects of limestone and fly ash or metakaolin have been elucidated in these studies. This has provided a methodology to realize increased OPC replacement without compromising performance.

In this study, a combination of limestone and slag is utilized as OPC replacement in order to develop binders that contain higher levels of cement replacement, yet result in performanceequivalent concretes. In addition to the alumina content in slag (which is typically higher than that in OPC but significantly lower than those typically found in fly ash or metakaolin) that facilitates limestone-aluminate synergistic reactions, slag demonstrates cementitious (albeit slow) and pozzolanic reactivity (11). Due to the latent hydraulicity of slag, slag-based cements show reduced early age strengths but they have been shown to attain significant compressive strengths at later ages $(12,13)$. The presence of fine limestone is expected to accelerate the early-age hydration in concrete containing slag. The synergistic effects of limestone and slag are explored in detail with respect to their contributions to the formation of hydration products and the development of strength and pore structure. Limestone powders of different size 57 distributions are blended with OPC and slag to obtain similar particle size distribution (PSD) as 58 the corresponding PLC-based mixture, which ensures that the total surface area available for 
59 the reaction is similar for all the mixtures. Up to $50 \%$ (by volume) of total OPC replacement is 60 studied.

\section{2.0 EXPERIMENTAL PROGRAM}

\section{$62 \quad 2.1$ Materials and Mixtures}

63 Commercially available Type I/II ordinary portland cement (OPC) conforming to ASTM C 150 64 and portland-limestone cement (PLC) conforming to ASTM C595 were the used in this study. 65 The PLC has a limestone content of $11 \%$ by mass (about $13 \%$ by volume). A nominally pure 66 limestone powder (purity $>95 \% \mathrm{CaCO}_{3}$, by mass) of four different median particle sizes -0.7 $67 \mu \mathrm{m}, 3 \mu \mathrm{m}, 10 \mu \mathrm{m}$ and $15 \mu \mathrm{m}$, conforming to ASTM C 568, and a slag conforming to ASTM C989 68 were used as partial cement replacement materials. Figure 1 shows the particle size 69 distributions of these materials. The median particle sizes are shown in these figures. Table 1 70 presents their respective chemical compositions.
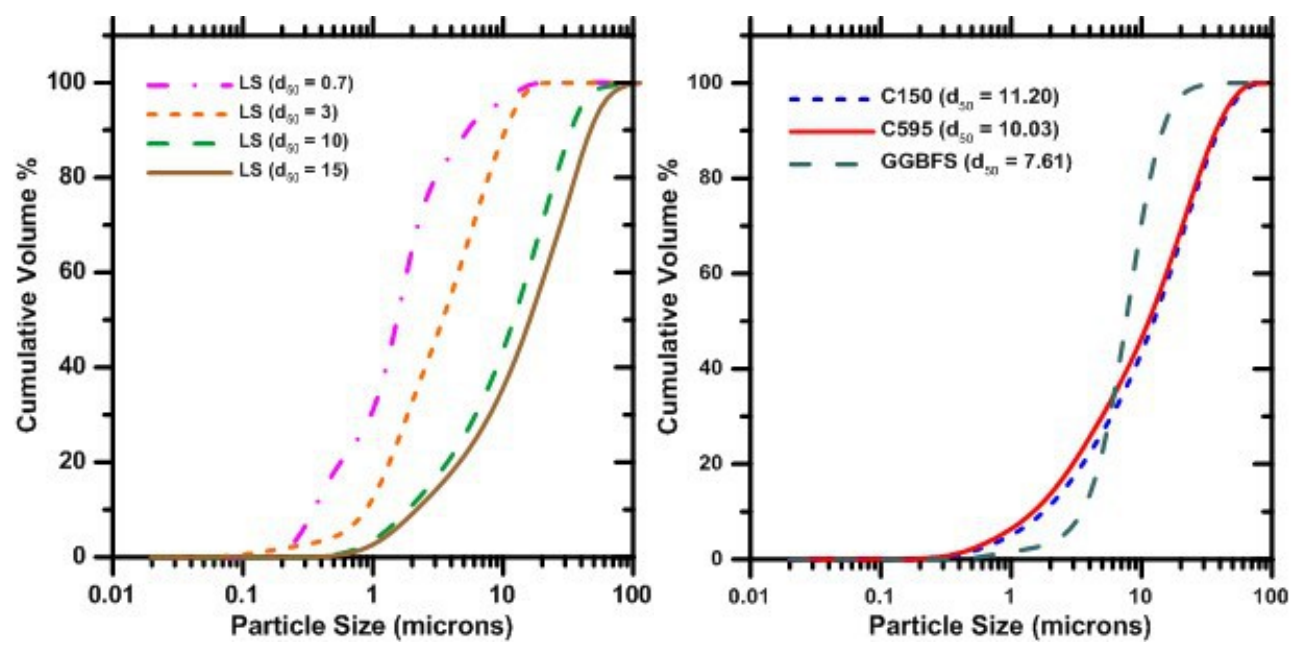

71

72

73

74

75

76

77

78 
Figure 1: Particle size distributions of: (a) parent OPC and PLC, and slag, and (b) limestone powders used in this study. The $d_{50}$ values (in! $m$ ) are shown in the figure legends.

81

82

Table 1: Chemical Compositions of materials (\% by mass) used in this study

\begin{tabular}{|l|c|c|c|c|c|c|c|c|c|}
\hline Material & $\mathbf{S i O}_{2}$ & $\mathbf{A l}_{2} \mathbf{O}_{3}$ & $\mathbf{F e}_{2} \mathbf{O}_{3}$ & $\mathbf{C a O}$ & $\mathbf{M g O}$ & $\mathbf{S O}_{3}$ & LOI & LS & $\begin{array}{c}\text { SSA } \\
\left(\mathbf{m}^{2} / \mathbf{k q}\right)\end{array}$ \\
\hline OPC - C150 & 19.60 & 4.09 & 3.39 & 63.21 & 3.37 & 3.17 & 2.54 & 2.90 & 452 \\
\hline PI C - C.595 & 1651 & 3.38 & 266 & 5680 & 261 & 280 & 417 & 1107 & 497 \\
\hline GGBFS - & 39.41 & 8.49 & 0.37 & 35.53 & 12.05 & 2.83 & 1.31 & - & 487 \\
\hline
\end{tabular}

84 The raw materials were proportioned by volume to obtain eleven different mixtures. Apart from 85 the plain OPC paste, three mixtures were proportioned where 20,40 , or $50 \%$ of OPC by volume was replaced by slag. Similarly PLC (with a limestone content of about $13 \%$ by volume) was used as the base material in pastes where 20,40 , or $50 \%$ of the clinker fraction in PLC was replaced using a combination of slag and limestone. For example, a mixture with a $40 \%$ replacement includes $31.3 \%$ of slag (externally added) and $8.7 \%$ of limestone (intrinsic to the PLC). In the next set of mixtures, 20,40 , or $50 \%$ of OPC was replaced by blending slag and limestone powder of four different sizes so as to match the PSD of the corresponding PLCbased binders. It should be noted that PLC has a limestone content of about $13 \%$ by volume ( $11 \%$ by mass), which is interground with the cement clinker during the manufacturing process. In this series, the limestone content was maintained at about $13 \%$ by volume, which is the same as that of the PLC. The sample nomenclature and the amounts of the constituents in the mixture are shown in Table 2. These mixtures are indicated as OPC-x, INT-x and BLD-x respectively, where $x$ represents the total replacement (by volume) of the cement clinker in the mixtures. $A$ volume-based water-to-powder ratio $(\mathrm{w} / \mathrm{p})_{\mathrm{v}}$ of 1.26 , which is approximately equivalent to a water-to-powder ratio of 0.40 by mass for the plain OPC system, was used.

Table 2: Volumetric percentages of the binder components for the mixtures considered in this study

\begin{tabular}{|c|c|c|c|c|c|c|c|c|}
\hline $\begin{array}{c}\text { Sample } \\
\text { ID }\end{array}$ & $\begin{array}{l}\text { OPC } \\
\text { (C150) }\end{array}$ & $\begin{array}{l}\text { PLC } \\
\text { (C595) }\end{array}$ & GGBFS & $\begin{array}{c}\text { Limesto } \\
\text { ne } \\
\text { (Total) }\end{array}$ & $\begin{array}{r}\text { LS } \\
0.7 ! \\
m\end{array}$ & $\begin{array}{c}\text { LS } \\
3 ! \\
\text { m }\end{array}$ & $\begin{array}{l}\text { LS } \\
10 ! \quad \mathrm{m}\end{array}$ & $\begin{array}{c}\text { LS } \\
15 ! \mathrm{m}\end{array}$ \\
\hline OPC-0 & 100.0 & 0.0 & 0.0 & 0.0 & - & - & - & - \\
\hline OPC-20 & 80.0 & 0.0 & 20.0 & 0.0 & - & - & - & - \\
\hline OPC-40 & 60.0 & 0.0 & 40.0 & 0.0 & - & - & - & - \\
\hline OPC-50 & 50.0 & 0.0 & 50.0 & 0.0 & - & - & - & - \\
\hline BLD-20 & 80.0 & 0.0 & 7.3 & 12.7 & 3.6 & 1.1 & 6.6 & 1.4 \\
\hline BLD-40 & 60.0 & 0.0 & 27.3 & 12.7 & 2.8 & 1.0 & 6.4 & 2.4 \\
\hline
\end{tabular}




\begin{tabular}{|l|r|r|r|r|r|r|r|r|}
\hline BLD-50 & 50.0 & 0.0 & 37.3 & 12.7 & 2.4 & 1.0 & 6.4 & 2.9 \\
\hline INT-13 & 0.0 & 100.0 & 0.0 & 12.7 & - & - & - & - \\
\hline INT-20 & 0.0 & 91.6 & 8.4 & 11.6 & - & - & - & - \\
\hline INT-40 & 0.0 & 68.7 & 31.3 & 8.7 & - & - & - & - \\
\hline INT-50 & 0.0 & 57.3 & 42.7 & 7.3 & - & - & - & - \\
\hline
\end{tabular}

102

103 In the mixtures where limestone was blended, four available limestone size distributions as 104 shown in Figure 1 (b) were used such that the overall PSD of the blend is similar to the PSD of 105 the PLC-based mixture at the same level of total replacement. The individual fraction of each 106 limestone size was calculated using an iterative solver to minimize the mean square error of the 107 final PSD of the blended and the interground mixtures. Size-matching in such a way ensures 108 that the total surface area available for the reaction is similar for the corresponding blended and 109 interground mixtures. However, intergrinding of portland cement clinker with limestone results in 110 limestone being the finer component in the composite system due to the fact that it is softer than 111 the clinker.

112 The volume percentages of different limestone sizes as obtained by matching of the PSDs of 113 the blended mixtures are also shown in Table 2. It should be noted that the size distribution 114 available for PLC is a composite distribution of cement and limestone and that the volume 115 percentages of OPC and limestone for PLC mixtures is expressed in terms of their relative 116 contribution to the amount of PLC in the corresponding mixtures. Figures 2(a), (b) and (c) show 117 the cumulative PSDs of the blended and interground limestone cement mixtures containing 118 slag, after particle size matching.

119

120

121

122

123

124

125 

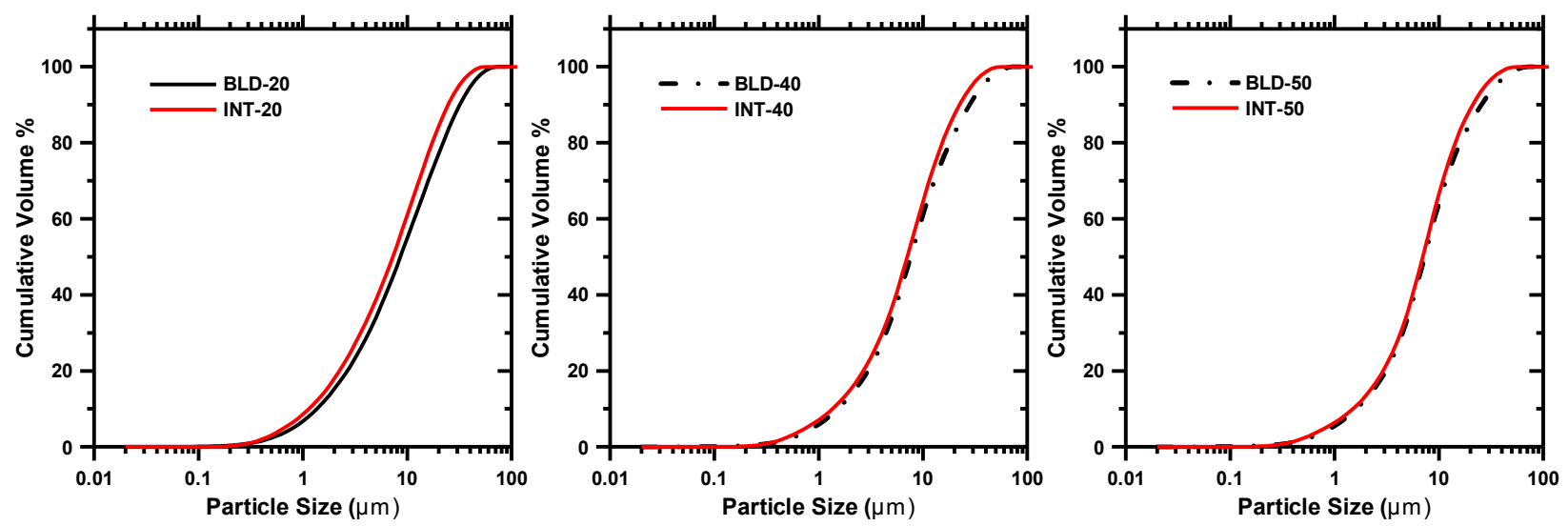

126

127

128

129

130

131

132

133

134

135

136

137

138

139

140

141

142

143

144

145

146

147

148

149

Figure 2: Comparison of particle size distributions (PSDs) for the interground and blended mixtures with cement replacement by volume of: (a) $20 \%$, (b) $40 \%$ and (c) $50 \%$

\subsection{Experiments}

\subsubsection{Isothermal Calorimetry}

The heat evolution during hydration was determined using isothermal calorimetry (TAM Air micro calorimeter 2700 Series) at a constant temperature of $25^{\circ} \mathrm{C}$ for 72 hours. To ensure accurate early age measurement and minimize the time to isothermal conditions, the powders and water were conditioned in an oven for 12 hours at $25^{\circ} \mathrm{C}$. The pastes (in triplicate) were then mixed using a laboratory mixer in accordance with ASTM C305 (14). Approximately $10 \mathrm{~g}$ of sample was extracted immediately, placed in a sealed sample vial to minimize evaporation and placed in the isothermal calorimeter to determine the heat release response.

\subsubsection{Compressive Strength Testing}

Compressive strength tests were carried out in accordance with ASTM C109 (15) on 50 mm mortar cubes cured in a moist environment $(>95 \% \mathrm{RH})$ and a temperature of $23 \pm 2^{\circ} \mathrm{C}$. Mortar cubes were prepared with a sand volume fraction of $50 \%$. The cubes were stored in the molds for 24 hours in covered conditions, after which they were demolded and stored until the desired testing age $(1,3,14,28,56$ and 90 days) in the moist-curing chamber. Three cubes were tested at each age.

\subsubsection{Thermal Analysis}

Simultaneous thermal analysis (STA) simultaneously measures the mass loss and heat flow associated with heating a sample over a defined temperature range. In this study, STA was carried out at ages of $1,3,7,14$, and 28 days. Powders were dry-blended prior to adding water, and the samples were mixed in accordance with ASTM C305. Paste samples were cured under 
150

151

152

153

154

155

156

157

158

159

160

161

162

163

164

165

166

167

168

169

170

171

172

173

174

175

176

177

178

179

180

181

182

sealed conditions at a temperature of $23 \pm 1^{\circ} \mathrm{C}$ until the desired testing age. Thermal analysis was completed using a Perkin Elmer STA 6000. Tests were carried out in a nitrogen environment, at a gas flow rate of $20 \mathrm{ml} / \mathrm{s}$. Duplicate samples were heated from ambient temperature to $995^{\circ} \mathrm{C}$ at a heating rate of $15^{\circ} \mathrm{C} / \mathrm{min}$. Heat flow curves from thermal analysis over this temperature range typically illustrate three distinct peaks - (i) loss of evaporable water and chemically bound water in $\mathrm{C}-\mathrm{S}-\mathrm{H}$ and ettringite, (ii) the dehydroxylization of calcium hydroxide, and (iii) the decarbonation of calcium carbonate. A minor peak corresponding to the decomposition of mono/hemi-carboaluminate species was also observed. Calcium hydroxide and residual calcium carbonate contents were determined using the stoichiometric relationships associated with their respective decomposition reactions and the mass loss associated with their decomposition temperatures. The chemically bound water $\left(w_{n}\right)$ is a measure of the degree of hydration of the portland cement, and is estimated by subtracting the mass loss associated with calcium carbonate from the loss on ignition of a dried sample (the mass at $110^{\circ} \mathrm{C}$ ), normalized by the mass of the dried sample. The consumed carbonate content is the percentage of carbonates consumed during the hydration process relative to the amount of carbonates initially present as determined from the mixture proportions.

\subsubsection{Mercury Intrusion Porosimetry (MIP)}

Paste samples were cured for 28 days under sealed conditions at a constant temperature of $23 \pm 1{ }^{\circ} \mathrm{C}$. The samples were crushed to an approximate size of $2 \mathrm{~mm}$, and then dried in an oven for 2 hours at $60{ }^{\circ} \mathrm{C}$. Two samples were tested corresponding to each specimen. This pretreatment method was found to produce consistent results in a previous study (4). A mercury intrusion porosimeter capable of exerting a maximum testing pressure of $414 \mathrm{MPa}$ was used. The relationship between pore diameter and intrusion pressure was determined using the Washburn equation (16) (Equation 1), where ' $d$ ' is the apparent diameter and ' $P$ ' is the applied pressure. '! ' is the surface tension of mercury and ' $\varphi$ ' is the mercury contact angle which are assumed to be $0.480 \mathrm{~N} / \mathrm{m}$ and $117^{\circ}$ respectively during intrusion. The contact angle of $117^{\circ}$ is typically used for the intrusion phase in oven dried cementitious materials (17-19), and thus was selected for this study.

Studies have identified potential inaccuracies in the determination of the pore size distribution using MIP $(20,21)$. However, the determinations of the total volume of mercury intruded and the critical (percolating) pore diameter which corresponds to the highest rate of volume intrusion into the specimen, have been suggested to be reliable $(17,22)$. 


\subsection{RESULTS AND DISCUSSIONS}

184

185

186

187

188

189

190

191

192

193

194

195

196

197

198

199

200

201

202

203

204

205

206

207

\subsection{Influence of Replacement Levels on Packing Characteristics in Simulated} Microstructures

The effect of particle packing on the properties of cement pastes and mortars has been well documented. Several studies have focused on optimizing particle packing arrangements to obtain high performance mixtures $(4,23,24)$. In the present study, the PSD of the component materials are used to determine packing characteristics, which can then be related to the early age hydration and strength development in cement-limestone-slag systems. In order to accomplish this, a microstructural stochastic packing model with periodic boundary conditions was implemented (25). The algorithm digitally packs spherical particles in a 3D REV (representative element volume, chosen here as $300 \times 300 \times 300 \mu \mathrm{m}^{3}$ ). The input volume fractions were determined based on the chosen $(w / p)_{v}$ and the number of particles of each class based on the respective particle size distributions. The key microstructural features such as the average number of nearest neighbors and the particle contact fractions were extracted from these digital microstructures for analysis. For any particle, the nearest neighbor is defined as a particle that lies either wholly or partially in the radial field of that particle, defined as a field with a radius of $(r+5) \mu \mathrm{m}$, where ' $r$ ' is the radius of the particle. The particle contact fraction is calculated as the fraction of nearest neighbor pairs in the microstructure. For instance, the slaglimestone contact fraction is calculated as the ratio of the total number of contacts between slag and limestone to the total number of contacts in the system (which includes cement-cement, limestone-limestone, slag-slag, and the three unlike particle contacts). Figure 3 shows representative $2 \mathrm{D}$ slices from $3 \mathrm{D}$ microstructures for the mixtures where OPC is replaced at a level of $50 \%$ by volume by slag and/or limestone.
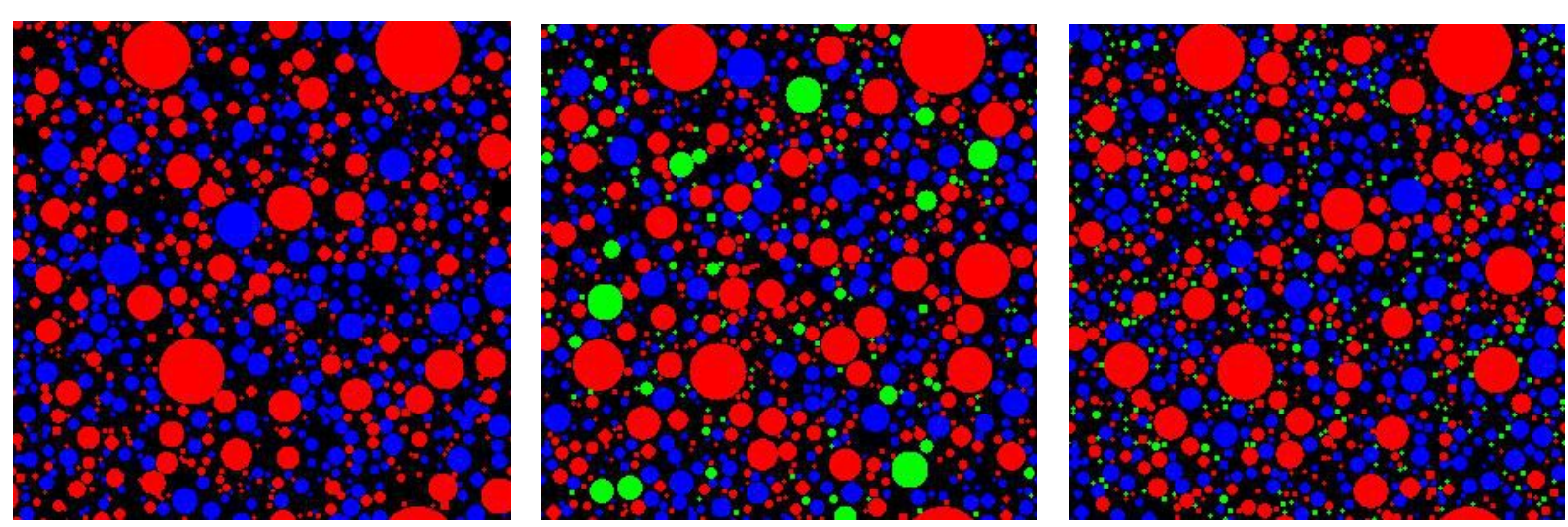
Figure 3: 2D slices captured from 3D RVEs generated using the particle packing model for mixtures where $50 \%$ of OPC by volume is replaced by slag and/or limestone: (a) OPC-50, (b) BLD-50 and (c) INT-50. The edge length of the RVE is $300 \mu \mathrm{m}$ and $\mathrm{w} / \mathrm{p}$ ratio by volume is 1.26 . Cement is represented in red, slag in blue, and limestone in green.

214 OPC was modeled using the available particle size distribution for $\mathrm{C} 150$ cement, whereas the 215 PLC was modeled as a two-phase material with contribution from both cement and limestone. However, only the composite particle size distribution was available for PLC and the details of the intergrinding process were not readily available. For the current study, the PSD of limestone in the PLC was determined by assuming that cement in the composite distribution has the same PSD as OPC (this is strictly not true since cement being harder than limestone, will be ground coarser in the intergrinding process; however this assumption is necessary). Considering that there is only about $13 \%$ of limestone in PLC and the median sizes of the OPC and PLC are not very different (11.2 and $10.03 \mu \mathrm{m})$, this can be considered to be a reasonable approximation. The limestone PSD in the PLC was then determined by calculating the median size of limestone using rule of mixtures and constructing a normal distribution about the median size. After obtaining individual PSDs of limestone and cement, the distributions were discretized to get the number of particles in a RVE of size $300 \mu \mathrm{m}$ using a packing fraction calculated from $(\mathrm{w} / \mathrm{p})_{\mathrm{v}}=$ 1.26. The results from the particle packing study are presented in Figure 4.

228
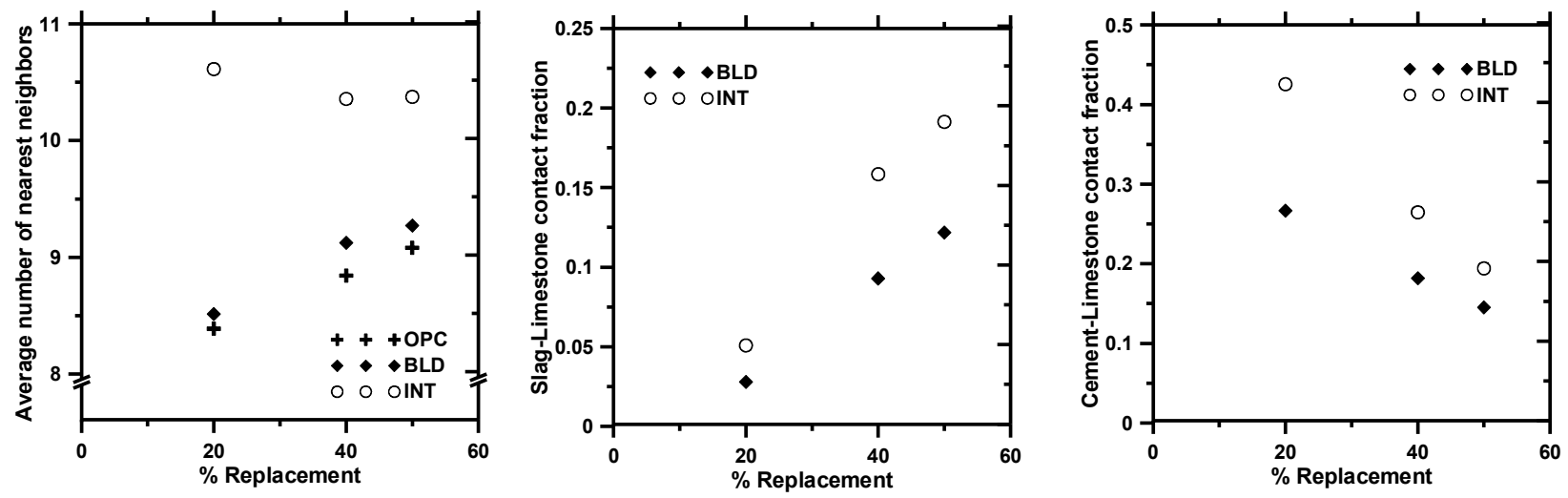

229

Figure 4: Key features extracted from microstructural packing models as a function of clinker 
234 Figure 4 (a) shows the average number of nearest neighbors for a particle in the microstructure. 235 This is an important factor that characterizes the proximity of the reacting species in the RVE 236 which is useful to understand the early age hydration behavior. Replacing OPC with slag or slag 237 and limestone increases the average number of nearest neighbors, and the increase is linear 238 with the replacement level. For the PLC mixture, a slight reduction in the number of nearest 239 neighbors is observed with increasing replacement levels because of the proportional decrease 240 in the amount of finer limestone content. Figures 4(b) and 4(c) show the contact fraction 241 between slag and limestone, and cement and limestone respectively in the blended and 242 interground systems. Since limestone acts as a heterogeneous nucleation site as well as 243 participates in the formation of carboaluminates in alumina-rich systems, the proximity of 244 cement and alumina-bearing slag to limestone particles is an important microstructural 245 parameter.

246 From Figure 4(b), it is noticed that the particle contact fraction between slag and limestone 247 increases with increasing clinker replacement level. The particle contact fraction is noted to be 248 much higher in the interground mixtures containing slag compared to the blended ones 249 containing slag. The difference between the particle contact fractions of the interground and 250 blended mixtures increases with the clinker replacement level, even though the fraction of 251 limestone in the blended mixtures is constant at $12.68 \%$ and the fraction of limestone in the 252 PLC-slag mixtures decreases in proportion to the clinker content. This is firstly because the 253 limestone in the interground mixtures is much finer compared to the limestone in the blended mixtures and secondly, higher amount of relatively fine slag $\left(d_{50}=7.61 \mu \mathrm{m}\right)$ replaces the cement in the interground mixtures (Table 2). This difference in the particle contact fractions is a possible reason for higher initial reactivity of the interground mixtures and the greater synergy between limestone and slag in the interground mixtures, as will be shown later. From Figure $4(c)$, it is observed that the cement-limestone contact fraction decreases with increasing clinker replacement level, as expected. However, the cement-limestone contact fraction in interground mixtures always remains higher than those in the blended mixtures. With increasing replacement level, the difference in particle contact fraction between the blended and interground mixtures reduces. This is because, in both cases, the dominant replacement material (slag) is finer than both the parent cements which are being replaced.

\subsection{Early Age Hydration Kinetics}

265 Early age hydration kinetics were determined using isothermal calorimetry at a temperature of $26625^{\circ} \mathrm{C}$ as described earlier. The heat flow plots normalized per gram of cement (i.e., the clinker 
267 fraction) obtained from isothermal calorimetry are shown in Figures 5(a)-(c) for the mixtures 268 shown in Table 2. The parent cements in each category of mixtures are represented using solid 269 lines and the samples with partial replacements are represented using dashed lines. Two major 270 peaks, corresponding to the hydration of the silicate and aluminate phases are found in all the 271 calorimetric signatures, as expected. Figure 5(a) shows the isothermal calorimetric response of 272 binary OPC-slag mixtures. It is observed that with increasing level of slag replacement, the 273 secondary peak corresponding to the hydration of the aluminate phase becomes more dominant 274 in comparison to the primary peak. This change in the trends is most likely due to the enhanced 275 rate of formation of AFm/AFmc phases (8) and is clearly noticeable in Figures 5 (a) - (c) as we 276 go from the parent cement paste to the paste with $50 \%$ overall replacement. In the case of 277 binary OPC-slag mixtures in Figure 5(a), the reaction follows a more conventional pathway as 278 that of OPC and leads to the formation of AFm phase from the reaction of ettringite with the 279 aluminates. The additional reactive alumina from slag results in a steeper slope of the 280 acceleration curve, and the slope increases with increasing slag content in the paste. Figure 2815 (b) shows the heat evolution for the pastes containing size-matched limestone and slag as 282 OPC replacement. It should be noted that all mixtures in Figure 5(b) have the same amount of 283 blended limestone. Therefore, the increase in the slope of the acceleration region (which is 284 higher than those in binary OPC-slag pastes) indicates the synergistic effect of slag and 285 limestone (note the increasing slag-limestone particle contacts in Figure 4(b)), where the 286 formation of a monocarbonate (AFmc) phase is preferred due to an increase in the overall alumina content in the mixture. Studies have indicated that the formation of AFmc phase is 288 favored over the formation of AFm phase for limestone containing mixtures (26). From Figures 5(a) and (b), it can also be observed that the primary heat flow peak is higher than the 290 secondary peak for OPC, while for mixtures containing slag and/or limestone, the opposite trend is observed. This is due to the enhanced aluminate hydration in the pastes containing a combination of limestone and slag. The peak also shifts towards earlier times with increasing cement replacement level in both OPC and the limestone blended mixtures, as is noticed in the 


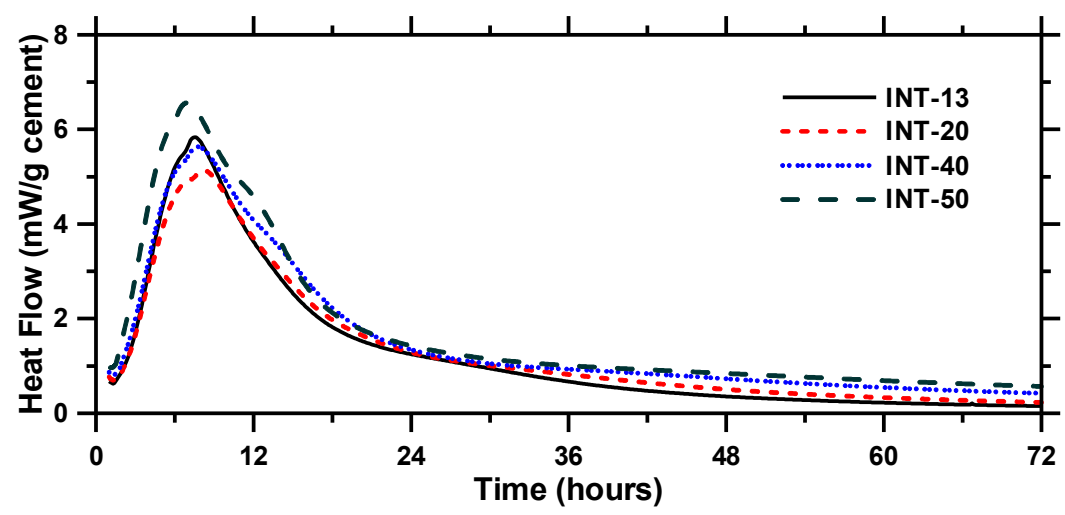

294

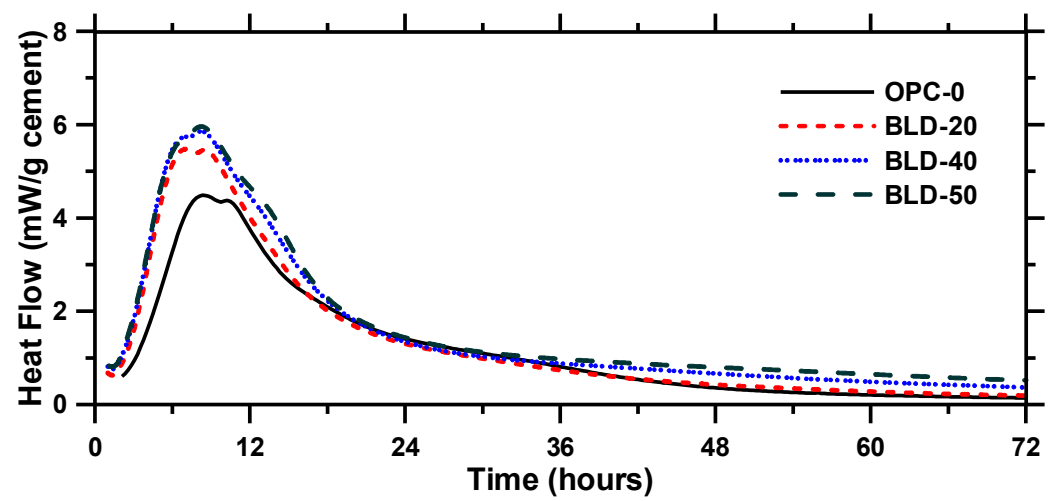

295

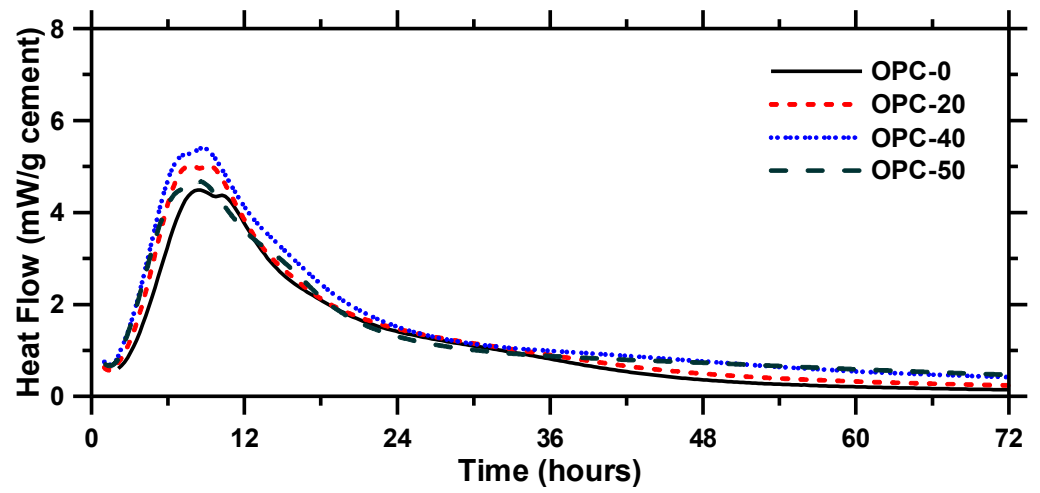
heat flow plots. 
Figure 5: Heat flow plotted as $\mathrm{mW} / \mathrm{g}$ cement for: (a) Slag replaced OPC mixtures, (b) Slag and blended limestone replaced OPC mixtures, and (c) Slag-replaced interground mixtures. Here cement indicates the clinker fraction. The uncertainty in heat flow is less than $1 \%$ based on measurements on triplicate samples.

Figure 5(c) depicts the heat flow response of the parent PLC paste and PLC-slag mixtures. It is noticed that the plain PLC paste and the PLC-slag blends show higher heat flow peaks as compared to other pastes at the same overall replacement level shown in Figures $5(a)$ and (b). Of particular importance among these samples is the parent PLC, which has about $13 \%$ limestone by volume interground with cement clinker. This paste shows a steeper acceleration curve and a higher heat flow peak value as compared to the plain OPC paste. When limestone is interground with portland cement clinker, the softer limestone is ground more readily than the harder portland cement clinker, resulting in finer limestone particles. The increased quantity of limestone fines significantly increases both the reactivity of the limestone and the surface area available for hydration product nucleation $(27,28)$, which is observed in the enhanced hydration rates. In the samples where PLC has been partially replaced with slag, beyond a $20 \%$ replacement level, it is noted that the rate of the heat flow as well as the peak heat flow increases, in relation to the plain PLC paste. Although the limestone content in the pastes proportionally decreases with increase in the replacement, the increasing slope of the acceleration region leads to discern that there is an increase in reactivity of limestone in the presence of slag. This synergistic effect of slag and limestone is attributed to the presence of reactive alumina in slag which along with the more reactive PLC, increases the consumption of limestone by the formation of AFmc phase as will be shown later.

It is observed from Figure 5 that in the deceleration region and beyond, the heat flow rate is higher for the mixtures containing slag as compared to plain OPC and PLC pastes. It is also noted that the difference in heat flow response in this period between the parent cements and the ones containing slag increases with increasing replacement level. This is attributed to the hydration of slag which takes place at a slower pace than cement. The hydration of slag is a slow process and the activity of slag in blended cement systems is predominantly pozzolanic in nature, controlled by the amount of alkali (calcium hydroxide) produced from cement hydration $(29,30)$. Thus, as the cement hydration progresses, it initiates the pozzolanic activity of slag which is noticeable from the deceleration region in the heat flow rate plots. 


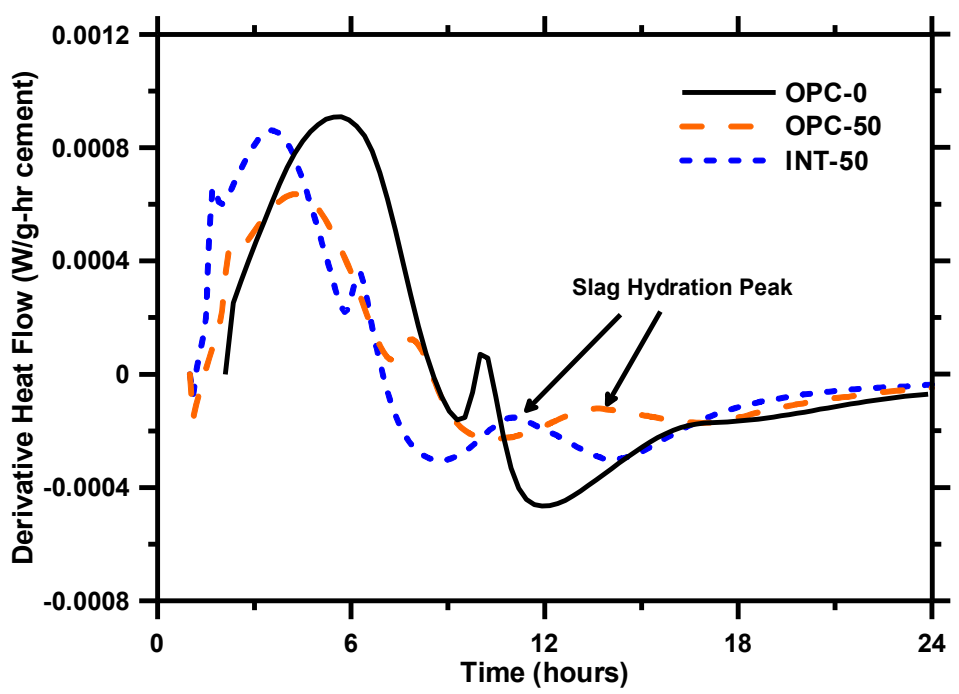

332

333

334

335

336

337

338

339

340

341

342

343

344

345

346

347

348
Figure 6: The derivative of the heat flow response of OPC and blended/interground mixtures to demonstrate the tertiary peak corresponding to the hydration of slag and accelerated hydration of slag in the presence of limestone.

The characteristic nature of the heat flow curves for all binary and ternary mixtures remains generally similar to that of their parent cement pastes except for a tertiary peak in the slagcontaining mixtures, corresponding to slag hydration at about 14 hours $(11,31,32)$. This peak, demonstrated as a hump in the deceleration portion of the heat flow curves, can also be identified on close observation of the heat flow plots in Figures $5(\mathrm{a}-\mathrm{c})$. This is readily shown in the derivative of the heat flow peak shown in Figure 6 for the mixtures containing $50 \%$ slag. Similar results are obtained for other replacement levels (not shown in the figure) as well. The earlier appearance of this peak in the heat flow response of the interground mixture containing limestone and slag as compared with the binary OPC-slag mixture indicates an acceleration in the hydration of slag in the presence of limestone. This could be due to the finer limestone acting as nucleation sites for the hydration of slag. 

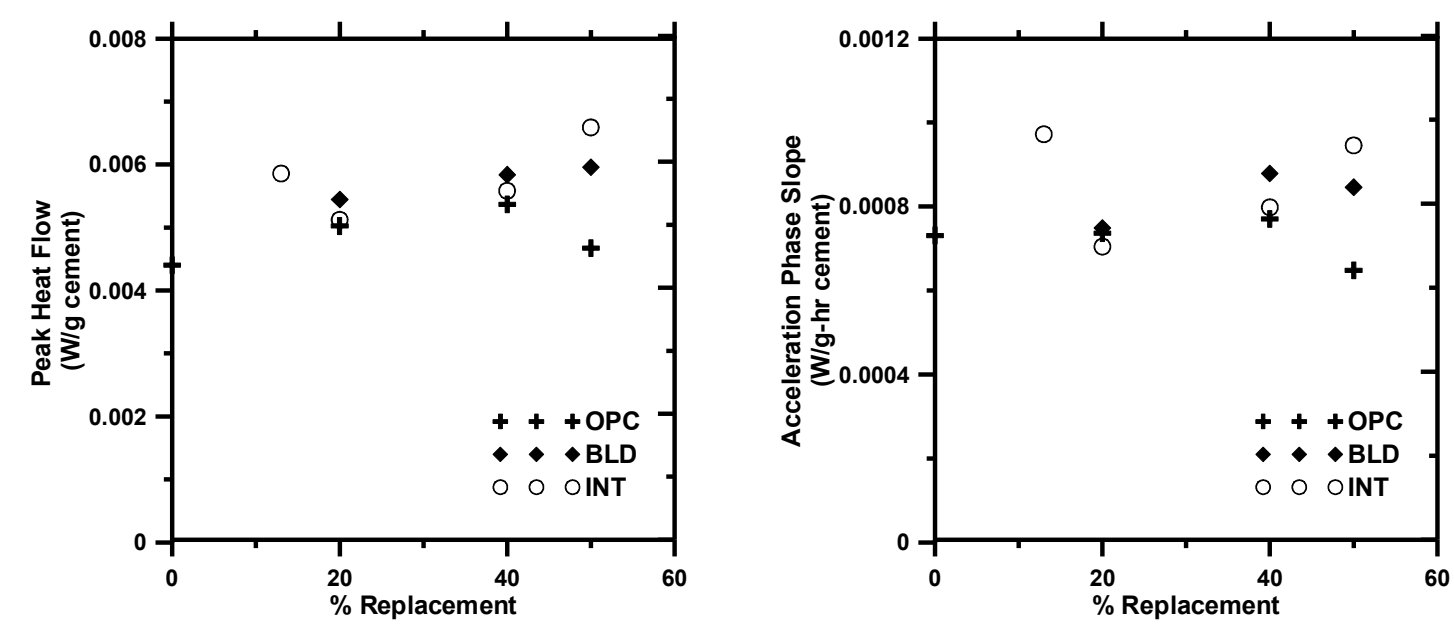

349

350

351

352

353

354

355

356

357

358

359

360

361

362

363

364

365

366

367

368

369

370

371
Figure 7: (a) Maximum heat flow, and (b) slope of acceleration period for blended OPC-slag and OPC-limestone-slag pastes, and PLC-slag pastes as a function of clinker replacement level.

To better characterize the hydration behavior and the slag-limestone interaction in these systems, the heat flow peaks for the aluminate phase and the slope of the acceleration region of the heat of hydration plots are shown in Figure 7 as a function of clinker replacement level. The heat flow peak values and the slopes of the acceleration period generally increase as OPC is replaced by slag in OPC-slag systems until a replacement level of $40 \%$, indicating the influence of a finer (than OPC) replacement material on early age hydration. Beyond that, the dilution effect dominates. At $50 \%$ total replacement level, the heat flow peak value as well as the slope of the acceleration period are highest for the PLC containing pastes, followed by the blended limestone mixture. This is attributed to the increase in the reaction rates due to the reactive alumina from slag and the finer limestone from the PLC. The rate of heat flow in the acceleration period as well as the peak heat flow value is positively influenced by acceleration due to the fine filler effect in the presence of limestone and the slag-limestone interaction, and negatively influenced by dilution effect due to the presence of limestone and slag fillers. The latter is better understood from the cumulative heat flow plots plotted per gram of binder (cement + slag) in Figure 8 . 
372

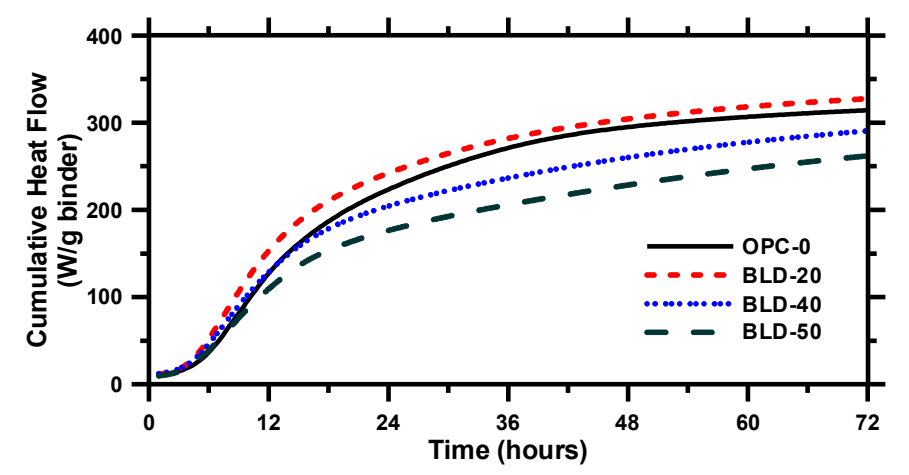

373

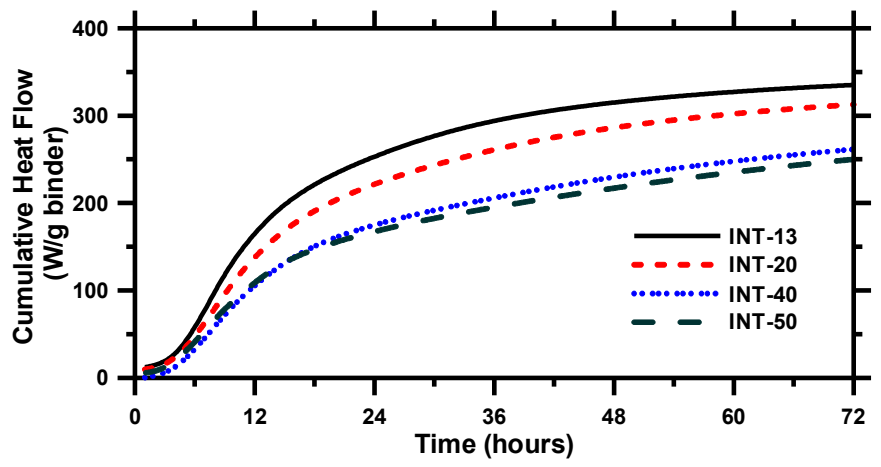

374

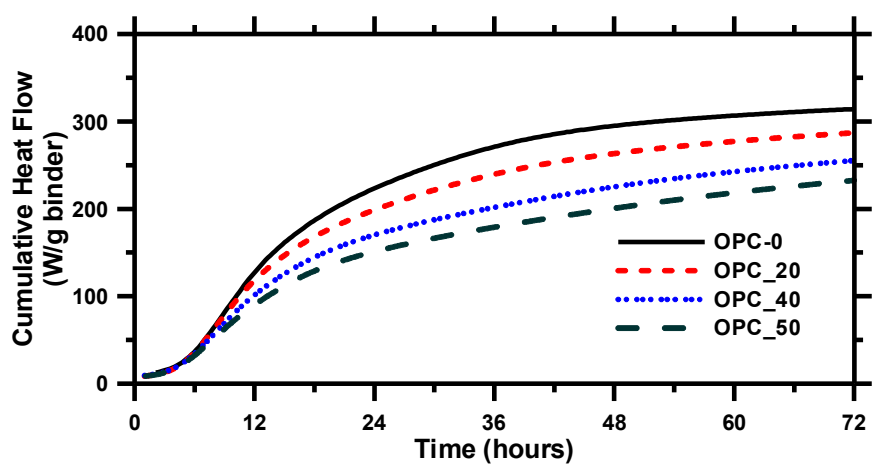

375 
Figure 8: Cumulative heat of hydration in W/g of binder (cement + slag) for: (a) volumetric replacement of OPC by slag, (b) OPC replaced by limestone-slag blends, and (c) interground portland-limestone cement (PLC) replaced by slag.

397 The cumulative heat content is an indication of the degree of hydration of the overall binder. A combination of cement and slag is considered as the binder. It is observed from Figure 8 that the cumulative heat released for all the mixtures is generally lower than that of the OPC paste at all times. This has important implications in early age thermal cracking of concretes. The cumulative heats are, though, not proportional to the cement content in the mixtures, which is due to the enhanced formation of the AFmc phase resulting in the consumption of limestone, and the hydration of slag. However, the contribution from the latter is not quite significant at 72

404 hours due to the latent hydraulicity of slag. On closer observation, it is found that the cumulative 405 heat flow values for the blended limestone mixtures containing slag are higher than those of the 406 OPC pastes containing slag alone at the same total replacement levels. This once again is an 407 indication of the increased limestone reactivity in the presence of slag.

\section{3.2 Compressive Strength Development}


409 Compressive strengths of $50 \mathrm{~mm}$ mortar cubes at ages of 1, 3, 7, 28, 56 and 90 days were 410 determined as described in Section 2.2.2. Figure 9 shows the evolution of compressive 411 strength over these ages for the mixtures considered in this study.

412
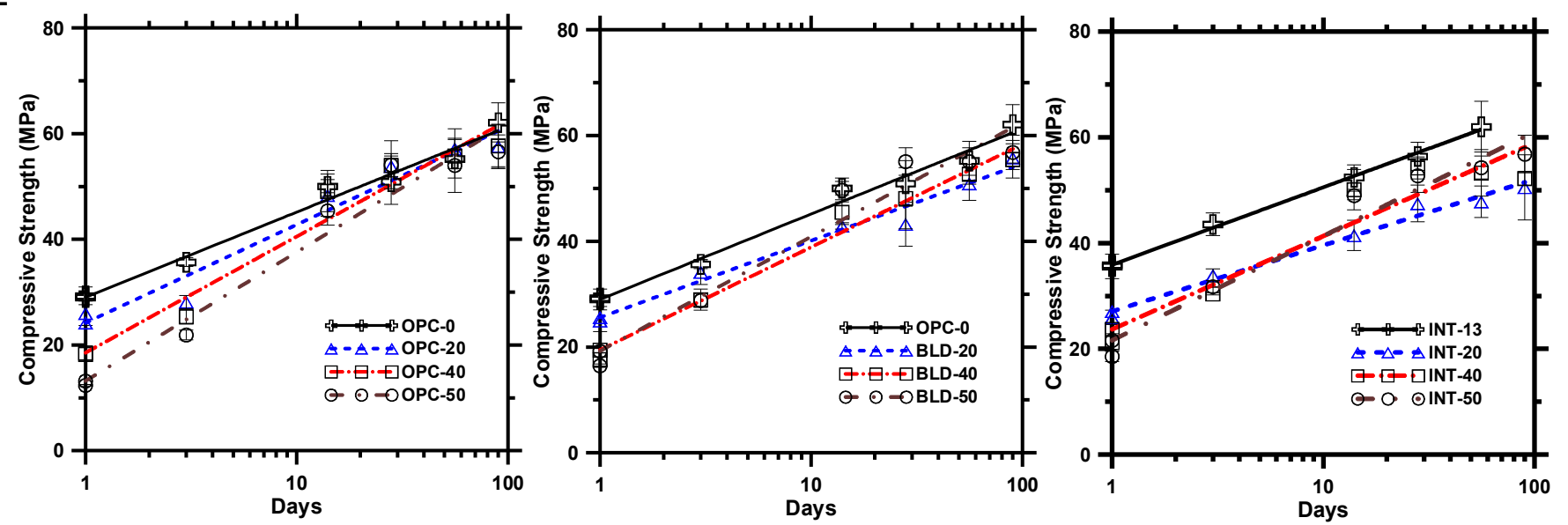

413 Figure 9: Compressive strength development of mortars with time: (a) volumetric replacement of

417 With respect to early age strengths, it can be immediately observed from all plots in Figure 9 418 that increasing cement (OPC or PLC) replacement levels decrease the compressive strengths 419 as expected. This is attributed to the higher volume of hydration products produced in the 420 mixtures with lower overall cement replacement at early ages. It is also observed from Figure 4219 (a) that the 1- and 3-day strengths are rather proportional to the OPC content in the mixtures, 422 indicating the effect of dilution in the early stages of hydration even though some slag hydration 423 has been noticed in the isothermal calorimetry curves. It is well known that the hydration of slag 424 is minimal at early ages $(33,34)$. However, in mixtures containing blended limestone (Figure $4259(\mathrm{~b}))$, the compressive strength values at early ages are slightly higher than when dilution is 426 dominant as in the case of OPC-slag blends. This is because of the presence of fine limestone 427 particles which act as nucleation surfaces and enhance the hydration process, and the increase 428 in the activity of limestone in the presence of slag which was explained earlier. It should be 429 noted that the silicate and aluminate components of slag have different rates of reaction, and 430 the aluminate phase reacts more rapidly as compared to the silicate phase (24). For the slag431 PLC blends in Figure 9(c), the 3-day strengths are independent of the replacement levels. This 432 is likely attributed to the dilution effect being compensated by the hydration of slag and the 433 increased reactivity of cement in the presence of finer limestone. The hydration of slag occurs 
earlier in the PLC-slag blends, more particularly in the mixtures containing $40 \%$ or $50 \%$ as discussed in the previous section.

436 The compressive strength values increase rapidly between 3 and 14 days of hydration. This is 437 due to the formation of secondary C-S-H as a result of hydration and pozzolanic reaction of slag 438 during this period. The extent of increase is more evident in the mixtures with higher 439 replacement levels. From Figures 9 (a-c), it can be clearly seen that the rate of increase in 440 strength for mixtures with $40 \%$ and $50 \%$ replacement levels is much higher as compared to the 441 mixtures with $20 \%$ replacement. This is because of the pozzolanic activity of slag in these 442 mixtures. The pozzolanic behavior is due to the reaction of the glassy phase which corresponds 443 to the silicates present in the slag, whereas the increase in the reactivity of limestone at early 444 ages is attributed to the presence of aluminates. Comparing between the OPC-limestone-slag 445 blended mixtures in Figure 9(b) and the PLC-slag mixtures in Figure 9(c), it can be noticed that 446 the difference in strengths for the parent cement paste and the blended mixtures containing slag 447 are higher for the PLC-slag system. This can be attributed to the much higher early age strength 448 of the parent PLC mortar owing to its increased fineness.

449 For the OPC-slag blends, the later age strengths (56 days and beyond) are comparable to that 450 of the parent OPC mixture. The hydration of slag and its pozzolanicity are responsible for this 451 behavior as will be shown using thermal analysis results later. A similar observation is noted for 452 the OPC-limestone-slag blends. For the PLC-slag blends, the strengths are slightly lower than 453 that of the plain PLC mortar, attributed to the increased fineness and reactivity of the PLC. 454 Comparing Figures $9(\mathrm{a}-\mathrm{c})$, it is observed that the mixtures with $40 \%$ or $50 \%$ replacement levels 455 obtain later-age strengths higher than those of the mixtures with $20 \%$ replacement level at different times depending on the mixture constitution. For the OPC-slag mixtures, this happens between 56 and 90 days whereas for the OPC-limestone-slag blends, this occurs between 10 and 14 days. For the PLC-slag mixtures, this occurs before 7 days, suggesting increased synergistic performance between limestone and slag. Since limestone is ground much finer in PLC, its reactivity with aluminates from slag is expected to be higher, which is represented in increased carbonate consumption for these systems as shown later. In most cases, the later age strengths at 56 days and 90 days for all the mixtures approach the strength of mixtures 463 made solely using their parent cements - OPC or PLC.

464 The lower rate of strength gain in the binary OPC-slag mixtures as compared to the ternary 465 mixtures containing limestone can be explained using the difference in reactivity of slag in the 
466 two systems. It is known from previous studies $(35,36)$ that the hydration of slag in cementitious systems is proportional to the amount of alkalis $(\mathrm{CH})$. The production of $\mathrm{CH}$, which is a result of the hydration of OPC, is lower in the case of the OPC-slag mixtures as compared to the mixtures containing limestone. Vance et al. (7) showed that hydration kinetics of OPC is positively influenced in the presence of fine limestone and therefore, in absence of fine limestone, lower relative quantities of $\mathrm{CH}$ have a detrimental effect on the reaction of slag in the

472 binary OPC-slag mixtures.

473 To obtain a better understanding of the influence of limestone and slag on the early and later 474 age strengths, the compressive strengths at 3 and 56 days are represented as a function of the 475 clinker factors in Figures 10(a) and (b) respectively. Clinker factor is defined as the ratio of the 476 volume of cement (OPC) in the dry mixture to the total volume of the powder. It is therefore an 477 effective criteria which indicates the sustainability of the mixture. From Figure $10(\mathrm{a})$, it is noted 478 that the 3-day compressive strengths of both the blended and interground mixtures containing 479 limestone are higher than those of the OPC-slag blends at all clinker factors, signifying the 480 influence of limestone in the early-age strength development process. Even at such an early 481 age, below a clinker factor of 0.6 , there is no strength reduction for both the blended and 482 interground systems containing limestone, which is attributable to the limestone-slag interaction 483 as well as the particle packing in these systems, as discussed in an earlier section. It is noted 484 that the slag-limestone interaction increases (Figure 4(b)) as the total level of replacement 485 increases in these systems, which leads to increased slag reaction, with limestone acting as a 486 heterogeneous nucleation site. The average number of nearest neighbors also increases as 487 shown in Figure 4(a), which leads to increase in the probability of formation of reaction products 488 and therefore increases the degree of reaction. The two factors mentioned above play an 489 important part in counteracting the effect of dilution at early ages and lead to increase in 490 strength at higher level of replacement. At later ages, as observed from Figure 10(b), the 491 compressive strengths remain rather unchanged irrespective of the clinker factor for all the 492 mixtures. 

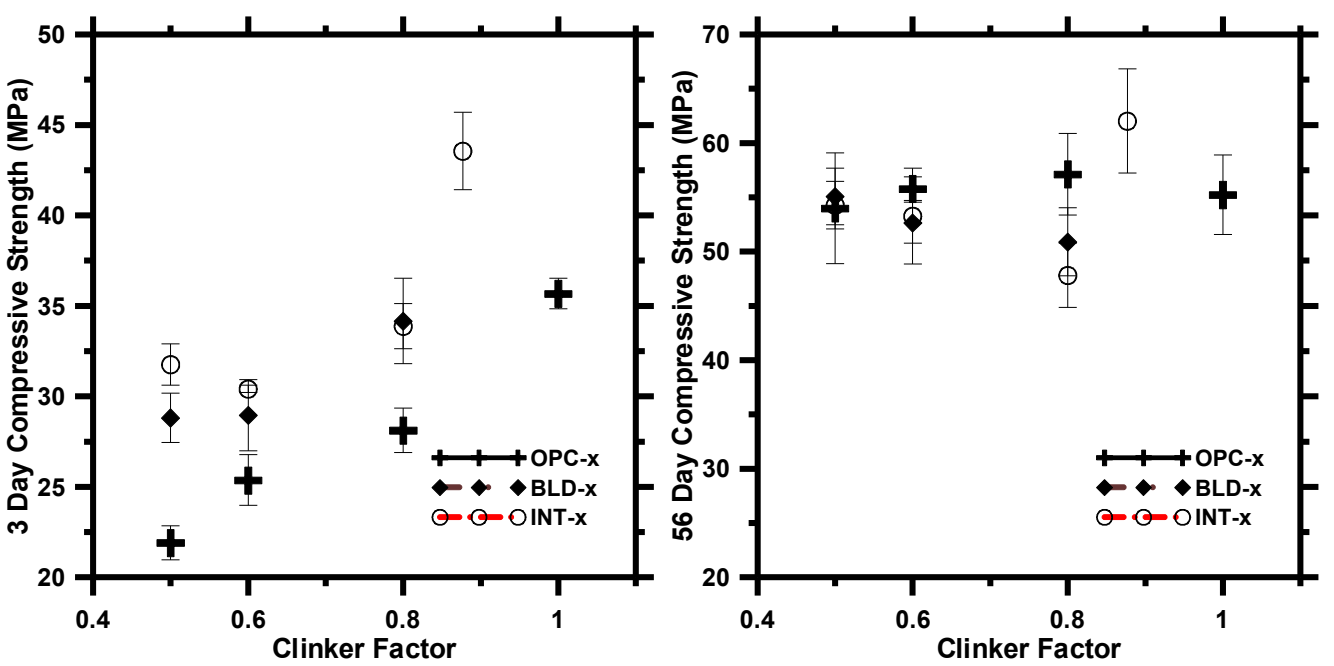

493

494 Figure 10: Compressive strength of all the binder systems studied as a function of clinker factor 495 at: (a) 3-days and (b) 56-days

\section{$496 \quad 3.3$ Hydration Products}

497 The progress of the hydration reaction was investigated using thermal analysis techniques. 498 Representative differential thermogravimetric (DTG) curves are shown in Figure 11. These curves show several distinguishable features: (i) all pastes show pronounced peaks at about $130^{\circ} \mathrm{C}$ and $450^{\circ} \mathrm{C}$, corresponding to the decomposition of $\mathrm{C}-\mathrm{S}-\mathrm{H}$ and ettringite, and the dehydroxylization of calcium hydroxide respectively, (ii) all pastes containing limestone show peaks at about $180^{\circ} \mathrm{C}$ corresponding to decomposition of hemi/mono-carboaluminates (37) and at approximately $750^{\circ} \mathrm{C}$ corresponding to the decarbonation of calcium carbonate.

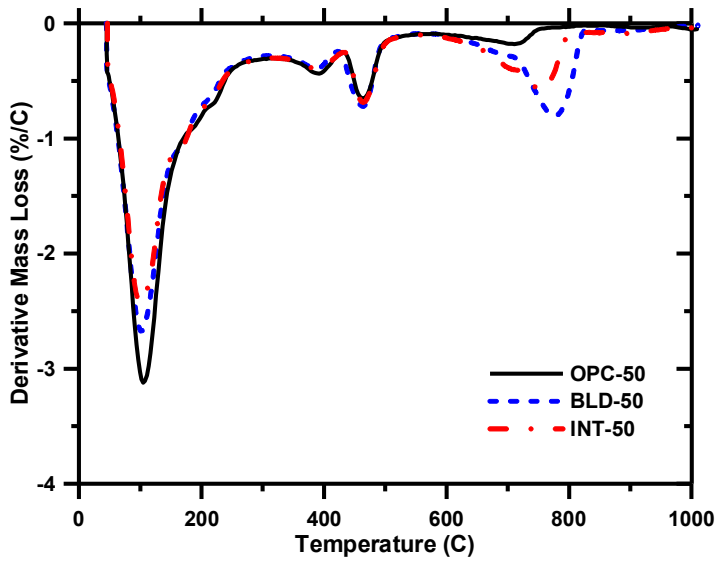

504

505

506

Figure 11: 28-day representative DTG profiles of pastes. The uncertainty in mass loss (TG) was less than $5 \%$ for duplicate measurements made at the same age.

507 


\subsubsection{Non-evaporable water contents}

509 Figures 12 illustrates the evolution of non-evaporable water $\left(w_{n}\right)$ content for all the pastes after 3 510 and 28 days of hydration. Non evaporable water content is considered to be one of the key 511 indicators of the progress of the hydration reaction process in hydraulic cements. An increase 512 in $w_{n}$ with time is noticeable between 3 and 28 days. In case of pastes containing slag, 513 especially after 28 days, $w_{n}$ denotes the contribution of the cement and the slag fractions in the 514 paste. Here, the progress of hydration in all the blended and interground mixtures studied is 515 evaluated as a function of the overall clinker replacement level, the amounts of limestone and 516 slag, and the process of intermixing (intergrinding vs. blending).

517

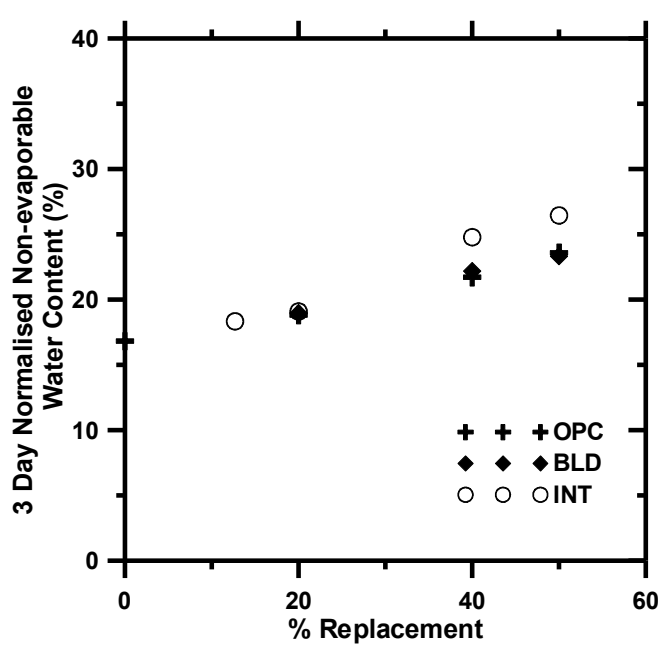

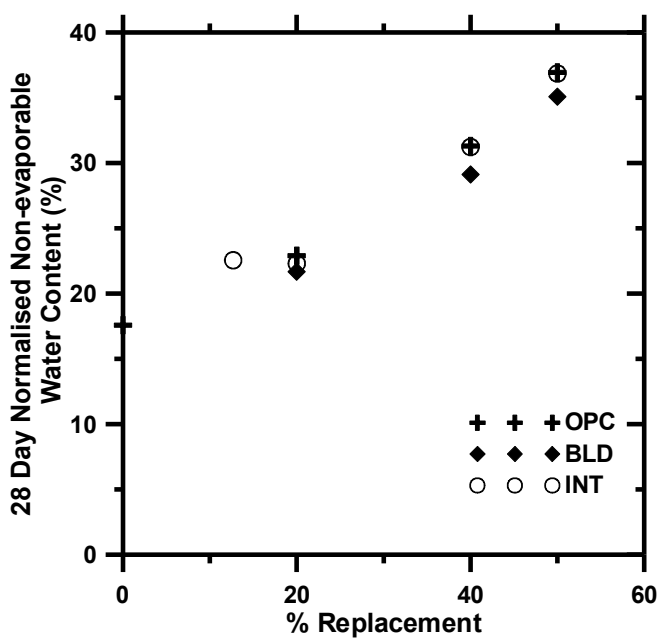

518

519

520

521

522

523

524

525

526

527

528

529

530

531

Figure 12: Non-evaporable water content normalized with respect to clinker factor as a function of the clinker replacement level at: (a) 3 Days and (b) 28 Days

As the slag content in the OPC-slag mixture increases, the normalized $w_{n}$ also increases at early ages (Figure 12(a)). However, this increase is not proportional to the clinker content in the mixes. This can be explained based on the fact that slag has slower reaction kinetics than cement, and it behaves mostly as inert filler at early ages. It may be argued that the filler effect of slag should lead to a higher cement hydration at higher replacement values; however that is compensated by the dilution effect. It is also noted that the 3-day values for $w_{n}$ are higher for the PLC-slag mixtures in comparison to the OPC-slag and OPC-slag-limestone blended mixtures. This is attributed to the enhanced hydration at early ages in the interground mixtures due to the presence of finer limestone particles acting as nucleation sites, as also suggested from the particle packing model with respect to the increased cement-limestone interaction (Figure 4(c)). At later ages, the hydration of cement continues to produce increased quantities of $\mathrm{CH}$, which 
532 enhances the hydration of slag (36). Thus, when the 28-day $w_{n}$ values are considered, they 533 increase more significantly with increasing slag content as can be noticed in Figure 12(b). Here,

534 it is also noticed that the $w_{n}$ values at a particular replacement level are relatively invariant of the 535 type of intermixing or the presence/absence of limestone.

\section{$536 \quad$ 3.3.2 CH contents}

537 Figure 13 presents the $\mathrm{CH}$ contents normalized by the clinker fraction for all the pastes. A 538 cursory look at the figures will result in the deduction that the actual $\mathrm{CH}$ contents (non539 normalized) reduce with increase in replacement level as expected, primarily attributed : (i) at 540 early ages to the reduced clinker fraction in the mixture, and (ii) at later ages to their 541 consumption by slag to produce secondary C-S-H. Between 3 and 28 days, the normalized $\mathrm{CH}$ 542 contents do not change appreciably, indicating that the same amount of $\mathrm{CH}$ produced by 543 cement hydration during this period is consumed by the pozzolanic reaction of slag to produce

544 additional C-S-H gel. This is apparent in the increase in $\mathrm{w}_{\mathrm{n}}$ values ranging between $15 \%$ and $54550 \%$ between 3 and 28 days, depending on the replacement level. 


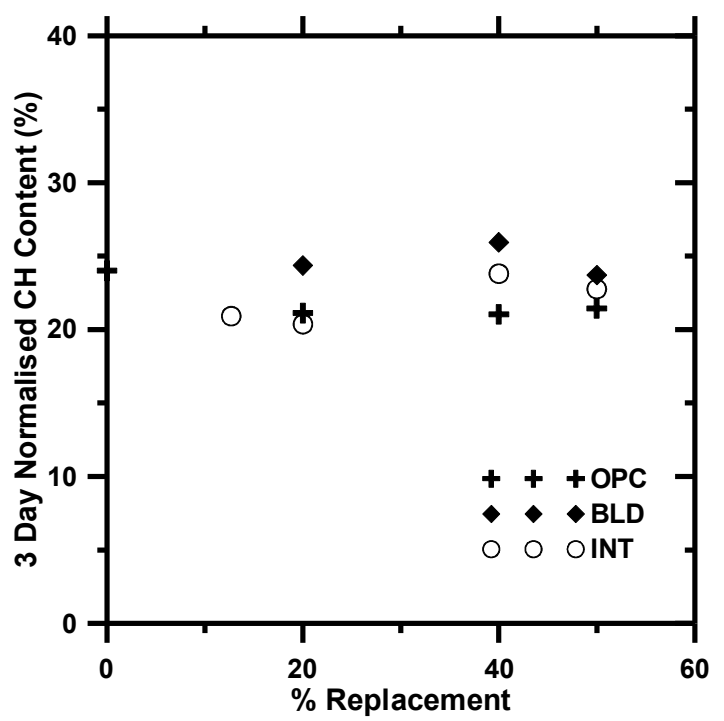

547

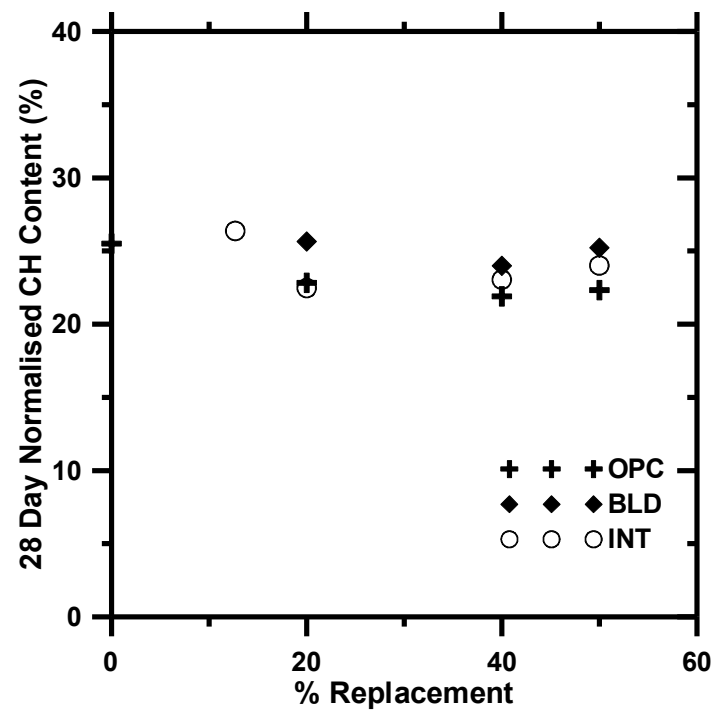

548

Figure $13-\mathrm{CH}$ content normalized with respect to clinker factor plotted as a function of the clinker replacement level at: (a) 3 Days and (b) 28 Days

551

\subsubsection{Carbonate consumption}


553 A quantification of the consumption of carbonate is essential to establish the reactivity of 554 limestone in the cementitious systems and identify conditions under which this can be 555 maximized to produce performance-equivalent low cement content concretes. Figures 14(a) and 556 (b) respectively show the carbonates consumed after 3 and 28 days of reaction in the blended 557 and interground systems containing slag. From Figure 14 (a), it is observed that more than $10 \%$ 558 of the carbonates are consumed in the PLC-slag mixtures within the first 3 days while for the 559 blended OPC-slag-limestone mixtures, the consumption is around $5 \%$. This is mostly attributed 560 to the finer limestone present in the interground (PLC-based) mixtures. However, for both 561 cases, the consumption of carbonates at 28 days is similar which indicates an increased rate of 562 consumption of limestone in the blended systems at later ages, possibly due to the slower 563 reactivity of coarser limestone in the blended pastes with the available aluminates. It is also 564 noticed from Figure 14 (b) that the consumption of carbonate increases with the clinker 565 replacement level, which is due to the formation of AFmc phase as will be quantified below.

566
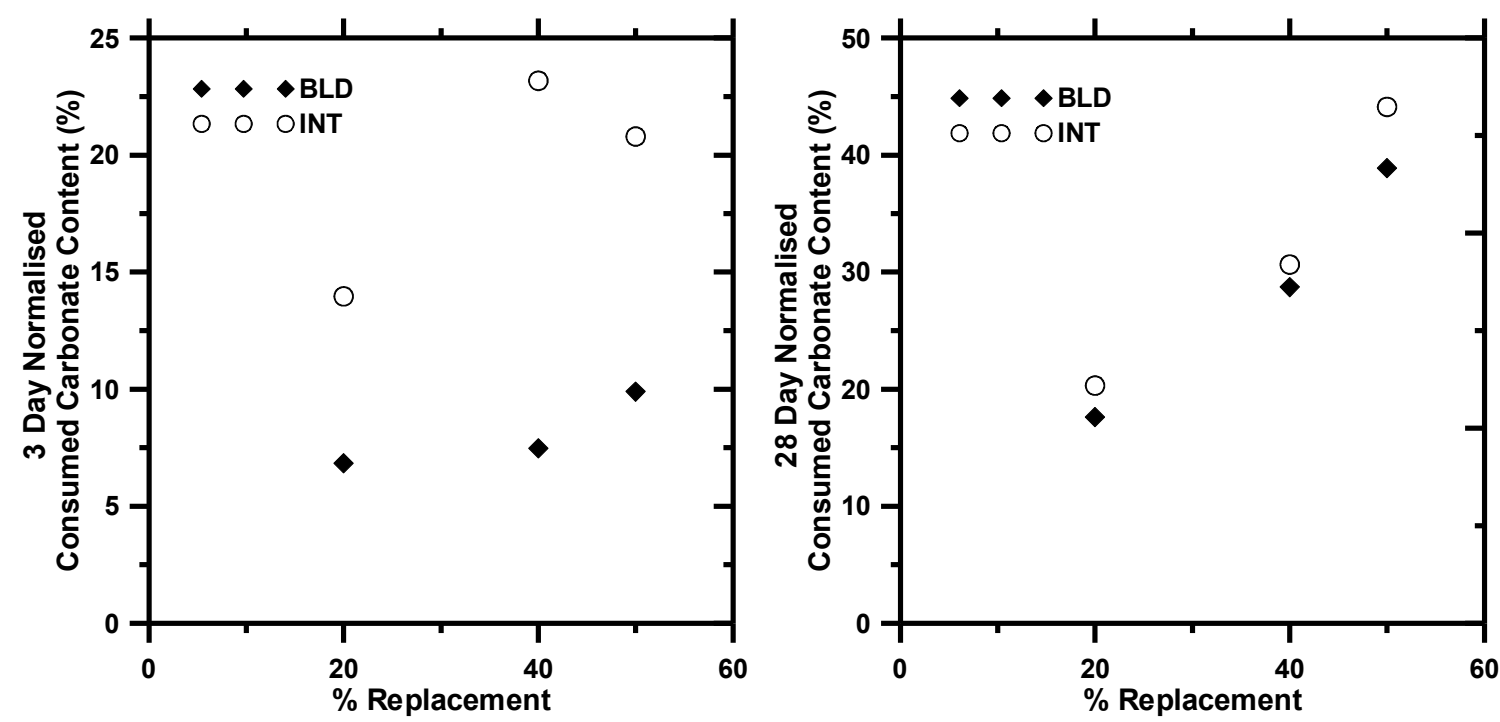

567 568

Figure 14: Consumed carbonate content normalized with respect to clinker factor plotted as a function of the clinker replacement level at: (a) 3 Days and (b) 28 Days

569

570 The higher reactive alumina content present in slag (8.7\%) alters the reaction pathway and 571 leads to the formation of carboaluminates instead of monosulfoaluminates. As a result of this, all 572 mixtures containing limestone and slag show an accelerated secondary peak in the isothermal 573 calorimetry plots in the initial hydration period corresponding to the formation of 574 carboaluminates. To quantify the synergistic effect of slag and limestone, the amounts of AFmc 575 phase were determined from the TGA plots in the temperature range between $150^{\circ} \mathrm{C}$ and $200^{\circ} \mathrm{C}$ 
576 (37). Figure 15 shows the relationship between consumed carbonate content and the AFmc 577 phase content in these mixtures after 3 and 28 days of hydration. An increasing amount of 578 AFmc phase corresponds rather linearly to an increase in carbonate consumption (or reduction 579 in carbonates detected by thermogravimetry), which is explained by the fact that the carbonate 580 reacts with the alumina present in cement and slag to form mono/hemi carboaluminates. 581 However it should also be noted that not all alumina present in slag reacts with the carbonate to 582 form the AFmc phase and is also bound in the denser pozzolanic C-S-H phase formed by the 583 hydration of slag (11).

584

585

586

587

588

589

590

591

592

593

594

595

596

597

598

599

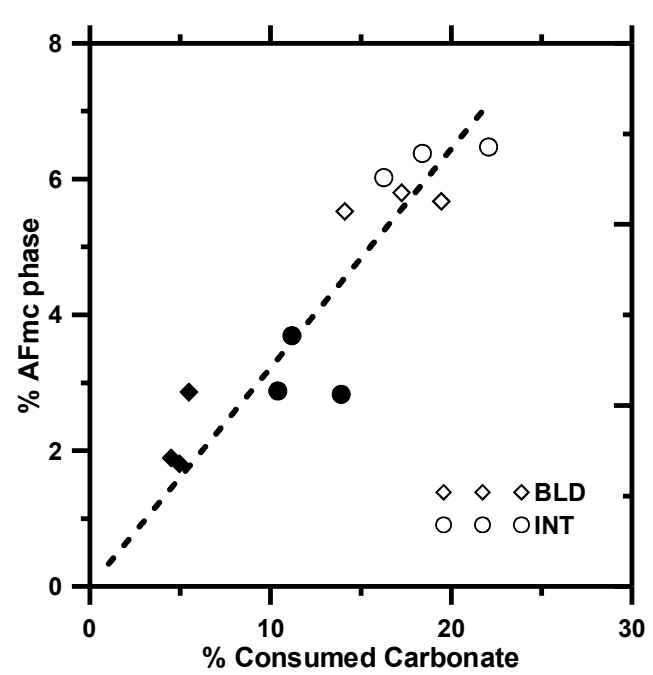

Figure 15: Plot showing positive correlation between the fraction of consumed calcium carbonate and AFmc phase in interground and blended mixtures. The solid symbols correspond to 3-day values and the empty symbols correspond to 28 day values.

The blended limestone in the OPC-slag-limestone mixtures and the interground limestone in the PLC mixtures are the only major source of carbonate in the respective pastes. There is a small amount of limestone in the OPC, and the residual carbonate contents in the blended pastes are adjusted with the amount of residual carbonate content of OPC at the same hydration age. It has been noted in previous studies that limestone participates to a limited extent in the cement hydration process by providing nucleation sites for the formation of hydration products and forming carboaluminates and hemi-carboaluminates by reacting with alumina phases present in the mixture and thereby stabilizing ettringite (38). In alumina-bearing pozzolanic material incorporated cement systems, the effect of limestone in stabilizing ettringite is much more obvious, which is noticeable in the results shown in Figure 15.

\subsection{Pore Structure}


600 The pore structure of the pastes was determined using MIP. Even though the pore size 601 distribution determined using MIP have been shown to be prone to error $(20,21)$, they are useful 602 for relative comparison.

603 To explore the influences of the addition of slag and limestone on the pore structure of these 604 systems, the porosity and critical pore diameters are presented in Figure 16. Several key 605 aspects are noted from Figure 16 (a). The OPC paste has a lower porosity than all the other 606 mixtures. The PLC-slag mixtures have comparable or slightly lower porosities than their blended 607 counterparts at the same total level of replacement. This is likely due to the enhanced 608 nucleation effect of finer limestone from the interground cement, which accelerates the cement 609 hydration as well as slag hydration process as was explained in the previous sections. The slag610 OPC binary blends have the least porosity as compared to all mixtures at the same clinker 611 replacement level. In other words, from a total pore volume standpoint, the absence of 612 limestone results in lower porosities because both the cement and slag are capable of hydrating 613 and producing reaction products. However, as the overall replacement level increases, it is 614 noted that the porosity increases for all the pastes, with the highest value noted for the pastes 615 with $50 \%$ overall replacement level in each of the categories. This is due to the reduction in the 616 cement content of the paste. Thus, although the total binder content remains the same, the 617 decrease in the cement content decreases the total volume of hydration products, since slag 618 does not achieve the same degree of hydration as compared to cement after 28 days of 619 hydration (39). On the other hand, it should also be noted that the increase in porosity is not 620 substantial in relation to the cement replacement level. This is because the decrease in cement 621 content is balanced to an extent by the pozzolanic activity of slag $(36,40)$ and the limited 622 participation of limestone in the reactions.

623 

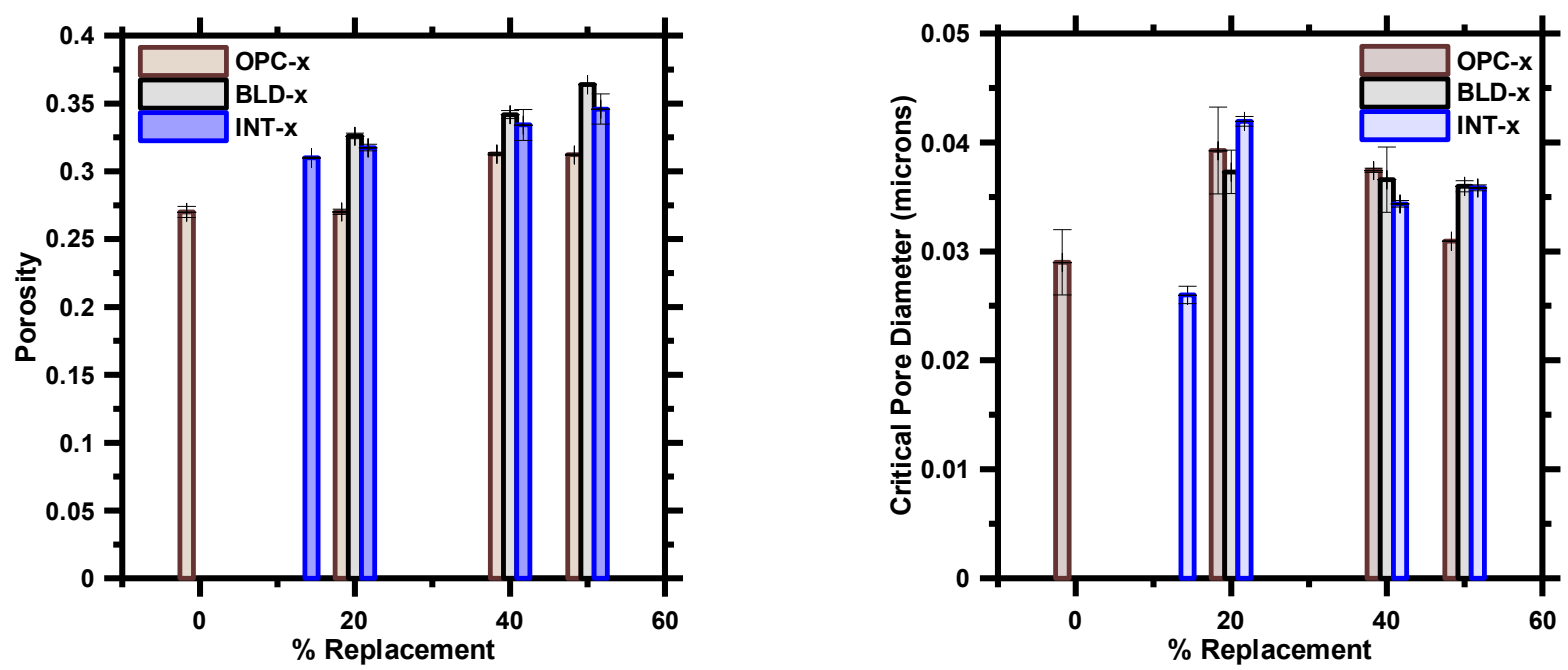

624

625

626

627

628

629

630

Figure 16 (b) shows the critical pore diameter in all the mixtures. The critical pore diameter is Figure 16 - (a) Porosity and (b) critical pore diameter for blended OPC-slag and OPClimestone-slag pastes, and PLC-slag pastes at 28 days as a function of clinker replacement level.

631 representative of the permeability of the sample, which is critical to the durability of concrete. It is noted that the critical pore diameter decreases with increasing level of replacement, indicating pore size refinement which is commonly reported with the use of pozzolanic materials (41). For the PLC-slag mixtures and the OPC-limestone-slag blended pastes, the critical pore diameters at higher replacement levels are similar to or lower than those of companion mixtures at a lower cement replacement level even when the corresponding porosities are higher. In addition, for all the pastes, the critical pore diameter varies within a small range (between 0.025 and $0.04 \mu \mathrm{m}$ ) demonstrating that the reduction in clinker factor does not adversely influence the transportcontrolling pore sizes in systems containing limestone and slag.

640 The development of binders containing high volumes (up to 50\%) of cement replacement using 641 a combination of slag and limestone was discussed in this paper. The influence of blending 642 limestone and slag with OPC or using slag along with PLC where limestone is interground 643 during the manufacturing process, was evaluated in detail. A particle packing model was utilized 644 to quantify the changes in the number of nearest neighbors and particle contacts, which have a 645 bearing on the hydration and reaction product formation in these systems. The heat flow peak 646 values and the slope of the acceleration period from isothermal calorimetry were found to be 647 highest for the interground limestone-slag systems, followed by the blended ternary systems, 
648 indicating the synergistic effect of limestone and slag in these mixtures. Slag hydration was also 649 noted to be accelerated in the presence of limestone, with the finer limestone in interground 650 systems providing increased acceleration relative to the blended ones.

651 The compressive strengths were found to be lower for the binary and ternary systems at early

652 ages than their parent OPC or PLC counterparts attributed to the dilution effect. However, the 653 presence of limestone resulted in an increased strength in both the blended and interground 654 states as compared to the OPC-slag blends. The later age strengths, even at $50 \%$ total 655 replacement were similar for the blended limestone-slag, and OPC-slag mixtures. The strength 656 gain between 3 and 28 days was found to be the highest in PLC-slag mixtures, followed by the 657 OPC-limestone-slag blends, and it was the lowest for the OPC-slag binary mixtures. This further 658 indicates the influence of limestone in these systems. As a function of the clinker factor in the 659 mixtures, the later age compressive strengths remained invariant of the limestone and slag 660 addition or method of addition. The synergistic effect of slag and limestone was also confirmed 661 by the linear correlation between the consumption of carbonates and the formation of AFmc 662 phase in the pastes. The presence of finer limestone in the PLC-containing pastes led to 663 increased carbonate consumption and thereby an increase in the formation of carboaluminates. 664 Although the total porosity in the pastes at later ages increased with cement replacement levels, 665 likely due to the incomplete reaction of slag, the critical pore diameters decreased, indicating 666 pore size refinement in the presence of slag and limestone. The comprehensive study reported 667 here can lead to the development of sustainable material design strategies using multiple668 material binders for concrete.

\section{5.0 ACKNOWLEDGEMENTS}

670 The authors gratefully acknowledge the National Science Foundation for the financial support 671 for this research (CMMI: 1068985). The materials were provided by U.S. Concrete, OMYA A.G, 672 Lehigh Hanson, and Holcim U.S., and are acknowledged. This research was conducted in the 673 Laboratory for the Science of Sustainable Infrastructural Materials at Arizona State University 674 and the support that has made this laboratory possible is acknowledged. The contents of this 675 paper reflect the views of the authors who are responsible for the facts and accuracy of the data 676 presented herein, and do not necessarily reflect the views and policies of the funding agency, 677 nor do the contents constitute a standard, specification, or a regulation.

\section{$678 \quad 6.0$ REFERENCES}

679 1. Worrell E, Price L, Martin N, Hendriks C, Meida LO. Carbon dioxide emissions from the 680 global cement industry. Annu Rev Energy Environ. 2001;26:303-29. 
681

682

683

684

685

686

687

688

689

690

691

692

693

694

695

696

697

698

699

700

701

702

703

704

705

706

707

708

709

710

711

712

713

714

715

716

717

718

719

720

721

722

723

724

725

726

727

728

729

730

731

2. Kumar A, Oey T, Kim S, Thomas D, Badran S, Li J, et al. Simple methods to estimate the influence of limestone fillers on reaction and property evolution in cementitious materials. Cem Concr Compos. 2013 Sep;42:20-9.

3. Vance K, Arora A, Sant G, Neithalath N. Rheological evaluations of interground and blended cement-limestone suspensions. Constr Build Mater. 2015 Mar 15;79:65-72.

4. Vance K. Early Age Characterization and Microstructural Features of Sustainable Binder Systems for Concrete [PhD Dissertation]. [Tempe, AZ]: Arizona State University; 2014.

5. Frohnsdorff G. Blended Cements: A Symposium. ASTM International; 1986. 170 p.

6. Osborne GJ. Durability of Portland blast-furnace slag cement concrete. Cem Concr Compos. 1999;21(1):11-21.

7. Vance K, Aguayo M, Oey T, Sant G, Neithalath N. Hydration and strength development in ternary portland cement blends containing limestone and fly ash or metakaolin. Cem Concr Compos. 2013 May;39:93-103.

8. Guillermo Puerta-Falla, Magdalena Balonis, Gwenn Le Saout, Gabriel Falzone, Aditya Kumar, Carolyn Zhang, et al. The Influence of the Aluminous Source on Enhancing Limestone Reactivity in Cementitious Materials. J Am Ceram Soc. 2015;

9. Matschei T, Lothenbach B, Glasser FP. The role of calcium carbonate in cement hydration. Cem Concr Res. 2007 Apr;37(4):551-8.

10. Oey T, Kumar A, Bullard JW, Neithalath N, Sant G. The Filler Effect: The Influence of Filler Content and Surface Area on Cementitious Reaction Rates. J Am Ceram Soc. 2013 Jun 1;96(6):1978-90.

11. Lothenbach B, Scrivener K, Hooton RD. Supplementary cementitious materials. Cem Concr Res. 2011 Dec;41(12):1244-56.

12. Bágel L. Strength and pore structure of ternary blended cement mortars containing blast furnace slag and silica fume. Cem Concr Res. $1998 \mathrm{Jul} ; 28(7): 1011-22$.

13. Hwang CL, Lin CY. STRENGTH DEVELOPMENT OF BLENDED BLAST FURNACE SLAG CEMENT MORTARS. 1986. p. 1323-40.

14. ASTM C305-13 Standard Practice for Mechanical Mixing of Hydraulic Cement Pastes and Mortars of Plastic Consistency. ASTM International, West Conshohocken, PA; 2013.

15. ASTM C109 / C109M - 12 Standard Test Method for Compressive Strength of Hydraulic Cement Mortars (Using 2-in. or [50-mm] Cube Specimens). ASTM International, West Conshohocken, PA; 2012.

16. Washburn EW. Note on a Method of Determining the Distribution of Pore Sizes in a Porous Material. Proc Natl Acad Sci U S A. 1921 Apr;7(4):115-6.

17. Windslow D, Diamond S. A Mercury Porosimetry Study of the Evolution of Porosity in Portland Cement: Technical Publication. JTRP Tech Rep [Internet]. 1969 Jan 1; Available from: http://docs.lib.purdue.edu/jtrp/1366

18. Bager DH, Sellevold EJ. Mercury porosimetry of hardened cement paste: the influence of particle size. Cem Concr Res. 1975 Mar;5(2):171-7.

19. Kumar R, Bhattacharjee B. Study on some factors affecting the results in the use of MIP method in concrete research. Cem Concr Res. 2003 Mar;33(3):417-24.

20. Moro F, Böhni $\mathrm{H}$. Ink-bottle effect in mercury intrusion porosimetry of cement-based materials. J Colloid Interface Sci. 2002 Feb 1;246(1):135-49.

21. Diamond S. Mercury porosimetry: An inappropriate method for the measurement of pore size distributions in cement-based materials. Cem Concr Res. 2000 Oct;30(10):1517-25.

22. Cook RA, Hover KC. Mercury porosimetry of hardened cement pastes. Cem Concr Res. 1999 Jun;29(6):933-43.

23. Lange $F$, Mörtel $H$, Rudert $V$. Dense packing of cement pastes and resulting consequences on mortar properties. Cem Concr Res. 1997 Oct;27(10):1481-8.

24. Kwan AKH, Fung WWS. Packing density measurement and modelling of fine aggregate and mortar. Cem Concr Compos. 2009 Jul;31(6):349-57. 
25. D. P. Bentz. CEMHYD3D: a three-dimensional cement hydration and microstructure development modeling package. Version 3.0. NISTIR 7232. US Dep Commer. 2005;

26. Matschei T, Lothenbach B, Glasser FP. The AFm phase in Portland cement. Cem Concr Res. 2007 Feb;37(2):118-30.

27. Vuk T, Tinta V, Gabrovšek R, Kaučič $V$. The effects of limestone addition, clinker type and fineness on properties of Portland cement. Cem Concr Res. 2001 Jan;31(1):135-9.

28. Kumar A, Oey T, Falla GP, Henkensiefken R, Neithalath N, Sant G. A comparison of intergrinding and blending limestone on reaction and strength evolution in cementitious materials. Constr Build Mater. 2013 Jun;43:428-35.

29. Pal SC, Mukherjee A, Pathak SR. Investigation of hydraulic activity of ground granulated blast furnace slag in concrete. Cem Concr Res. 2003 Sep;33(9):1481-6.

30. Odler I. Special Inorganic Cements. CRC Press; 2003. 391 p.

31. Wu X, Roy DM, Langton CA. Early stage hydration of slag-cement. Cem Concr Res. 1983 Mar;13(2):277-86.

32. Wu X, Jiang W, Roy DM. Early activation and properties of slag cement. Cem Concr Res. 1990 Nov;20(6):961-74.

33. Beushausen $\mathrm{H}$, Alexander M, Ballim Y. Early-age properties, strength development and heat of hydration of concrete containing various South African slags at different replacement ratios. Constr Build Mater. 2012 Apr;29:533-40.

34. Menéndez G, Bonavetti V, Irassar EF. Strength development of ternary blended cement with limestone filler and blast-furnace slag. Cem Concr Compos. 2003 Jan;25(1):61-7.

35. W. Chen HJHB. The hydration of slag, part 2: reaction models for blended cement. J Mater Sci. 2007;42(2):444-64.

36. Kolani B, Buffo-Lacarrière L, Sellier A, Escadeillas G, Boutillon L, Linger L. Hydration of slag-blended cements. Cem Concr Compos. 2012 Oct;34(9):1009-18.

37. Damidot D, Lothenbach B, Herfort D, Glasser FP. Thermodynamics and cement science. Cem Concr Res. 2011 Jul;41(7):679-95.

38. Kim MS, Jun $\mathrm{Y}$, Lee $\mathrm{C}$, Oh JE. Use of $\mathrm{CaO}$ as an activator for producing a pricecompetitive non-cement structural binder using ground granulated blast furnace slag. Cem Concr Res. 2013 Dec;54:208-14.

39. Escalante JI, Gómez LY, Johal KK, Mendoza G, Mancha H, Méndez J. Reactivity of blastfurnace slag in Portland cement blends hydrated under different conditions. Cem Concr Res. 2001 Oct;31(10):1403-9.

40. Richardson IG, Groves GW. Microstructure and microanalysis of hardened cement pastes involving ground granulated blast-furnace slag. J Mater Sci. 1992 Nov 1;27(22):6204-12.

41. Courard L, Michel F. Limestone fillers cement based composites: Effects of blast furnace slags on fresh and hardened properties. Constr Build Mater. 2014 Jan 31;51:439-45. 